\title{
Key technologies and the implementation of wind, PV and storage co-generation monitoring system
}

\author{
Xianliang TENG ( $\square)$, Zonghe GAO, \\ Yingyuan ZHANG, Hua HUANG, Lili LI, \\ Tingting LIANG
}

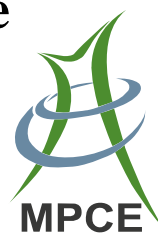

\begin{abstract}
The coordinated control of multiple-sources including wind, photovoltaic (PV) and storage brings new challenges to traditional dispatch and control technologies. This paper firstly introduces a framework of wind, PV and storage co-generation monitoring system. Then, key technologies of co-generation monitoring system including day-ahead optimal dispatching, active power coordinated control and reactive power and voltage control are proposed. The framework and the techniques described in this paper have been applied in the National Wind, Photovoltaic, Storage and Transmission Demonstration Project of China, and their validity have been tested and verified.
\end{abstract}

Keywords Wind, photovoltaic (PV) and storage, Co-generation monitoring system, Day-ahead optimal dispatching, Active power coordinated control, Reactive and voltage control, Coordination control

\section{Introduction}

Because of the increasing energy crisis and environmental pollution, energy saving and emission reduction are of vital importance for social development. Large-scale utilization and centralized integration of renewable energy in China becomes an inevitable trend. However, wind and solar energy are much different from conventional

CrossCheck date: 21 April 2014

Received: 16 September 2013/Accepted: 5 May 2014/Published online: 12 June 2014

(C) The Author(s) 2014. This article is published with open access at Springerlink.com

X. TENG, Z. GAO, Y. ZHANG, H. HUANG, L. LI, NARI

Group Corporation, Nanjing 211102, China

$(\bowtie)$ e-mail: tengxianliang@ sgepri.sgcc.com.cn

T. LIANG, Zhangjiakou Wind and Solar Power Energy

Demonstration Station Co. Ltd, Hebei, China resources, their inherent characteristics of stochastic volatility and intermittency bring massive challenges to the dispatch and operation of power systems [1-3]. In experimental research field, large-scale energy storage technologies have drawn much attention. They are expected to be effective ways to increase the penetration of renewable energy power generation [4-7].

The National Wind, Photovoltaic, Storage and Transmission Demonstration Project has been constructed by the State Grid Corporation. The project is located in Zhangbei county, Hebei province, which aims to increase the penetration of large-scale renewable energy generation.

At present, some achievements and application practices have been realized in renewable energy generation monitoring. Reference $[8,9]$ analyzes the technical requirements about wind power integrating into the grid and introduces a scheme of wind farm monitoring system which aims to make wind farm a predictable, adjustable and high-quality power supply. Reference [10] presents a structure of PV generation monitoring system for data processing and analysis, which also makes remote control available. However, the system does not meet the technical requirements of PV power generation with grid-friendly interaction [3]. Besides configuration, some key technologies in grid connection and data monitoring for a small-scale wind-solar complementary generation system are described in reference [11]. However, coordination control of wind power and PV power is not involved. Reference [12] proposes a solution of operation and control for hybrid energy storage system. Wind power fluctuations can be stabilized by two controllers which are interconnected with ultra-capacitor storage and battery storage respectively. But the battery storage cannot participate in the process of power regulation more flexibly. Reference [13] discusses the general principles of control strategy for wind, PV and storage co-generation system. But a complete set of implementation scheme is not put forward. 
Reference [14, 15] explains the operation and management technologies for large-scale wind power dispatch and control in provincial dispatching center. Control schemes of AGC and AVC are discussed. And the framework of on-line power and voltage control to wind farm are put forward at the same time.

In general, application of wind PV and storage co-generation monitoring system is still concerned with the theoretical research and simulation phase. There are few engineering applications and operating experiences. It is expected to do further research in models and strategies of multiple-source complementary coordination control.

Based on the National Wind, PV, Storage and Transmission Demonstration Project, this paper mainly studies the coordinated operation mechanism and focuses on three key dispatching technologies discussed in the following. In addition, the proposed technical schemes have been tested and verified in the practical project.

1) Day-ahead optimal dispatching: An optimization model aiming to maximize the benefits of the cogeneration system is given in this paper. Meanwhile, penalties for multi-point coupling fluctuations of generating curves are considered and are added to the optimal object.

2) Active power coordinated control: An active power coordinated control strategy is proposed to satisfy different operation requirements including co-generation output fluctuation smoothening, planned generation output tracking and frequency regulation participating. Taken co-generation and single plant into account, this paper designs various combinational control modes, which can be flexibly configured.

3) Reactive power and voltage control: The general ideas for coordinated control are presented as follows. Wind turbines, PV inverters and storage devices are given priority during the regulating process. Static var generator (SVG) is expected to respond as quickly as possible. Capacitor switching acts as a supplementary method. Cooperative and coordinated control of reactive power resources can be realized in multiple modes, such as continuous or discrete mode, high speed or low speed mode and voltage command or reactive power command mode.

\section{Framework of the wind, PV and storage co- generation system}

The National Wind, PV, Storage and Transmission Demonstration Project plans to construct $500 \mathrm{MW}$ wind farms, a $100 \mathrm{MW} \mathrm{PV} \mathrm{power} \mathrm{station} \mathrm{and} \mathrm{a} \mathrm{corresponding}$

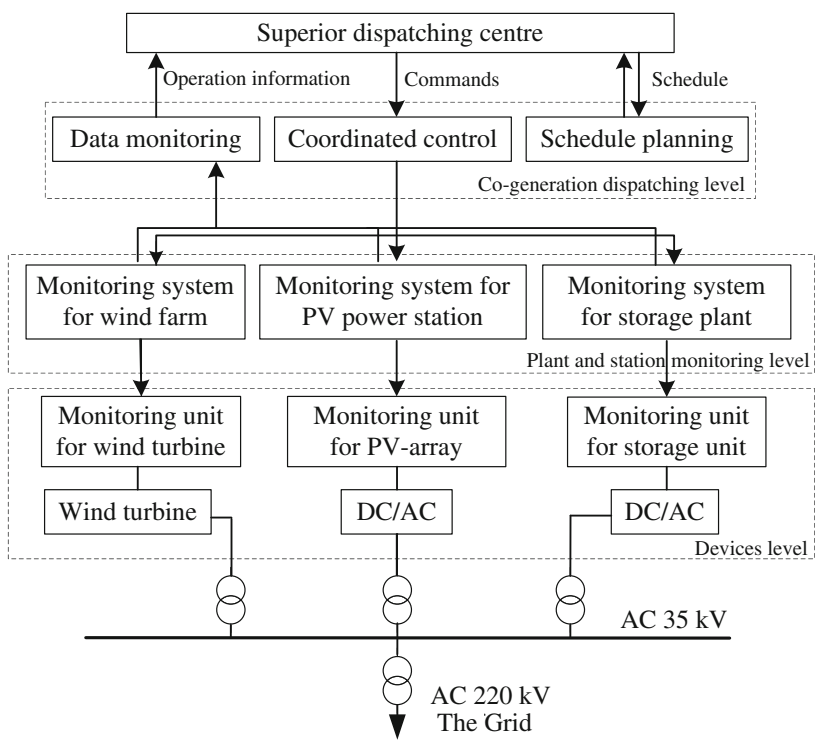

Fig. 1 Framework of the wind, PV and storage co-generation system

energy storage plant. The first-phase project was completed and put into operation on December 25, 2011. Construction of the first-phase project includes $100 \mathrm{MW}$ wind farms, a $40 \mathrm{MW}$ PV power station, a $20 \mathrm{MW}$ energy storage plant and a $220 \mathrm{kV}$ smart substation. At present, the project is the largest comprehensive renewable energy utilization platform worldwide, aiming to make the renewable energy involved predictable, controllable and dispatchable. Besides, the grid capability for large-scale renewable energy integrating can be effectively improved.

The general framework of the demonstration project consists of three levels as shown in Fig. 1. They are co-generation dispatching level, plant and station monitoring level, and devices level, among which, co-generation dispatching level is a bridge connecting the co-generation system to the superior dispatching centre. On one hand, this level designs open and coincident models of the co-generation system and provides operation analysis support for superior dispatching centre. On the other hand, as a controlling centre of the whole demonstration project, this level carries on intelligent analysis and decision-making, and the coordinated control among wind farms, PV power station and storage plant is realized. Plant and station monitoring level is used to monitor each plant and upload real-time operation information of every device. This level also receives control commands sent by co-generation dispatching level and distributes to control units in devices level simultaneously.

Wind, PV and storage co-generation panoramic monitoring system is developed and applied in co-generation dispatching level. The monitoring system offers a variety of advanced applications which mainly include Day-ahead optimal dispatching, active power coordinated control, 


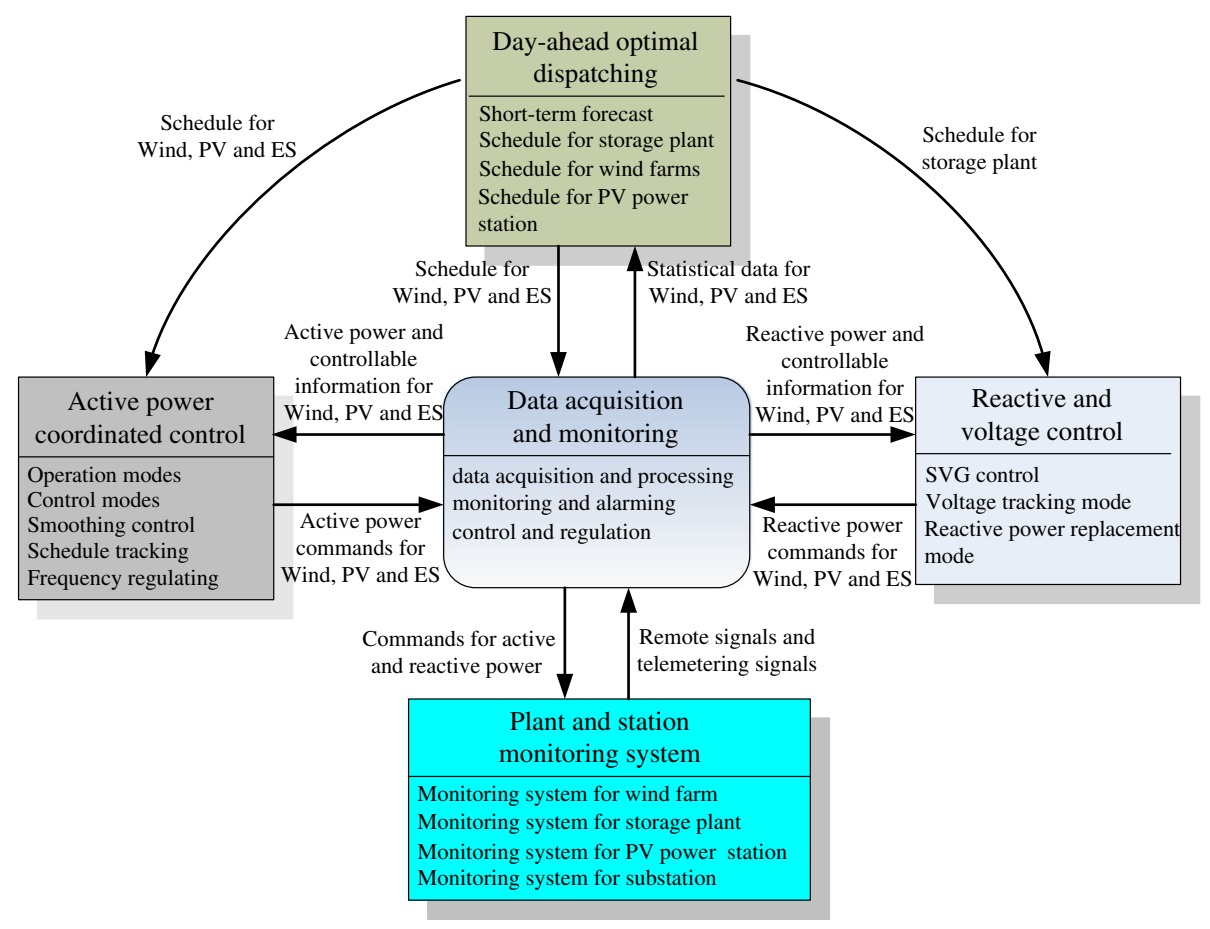

Fig. 2 Logical relationship among each applications of the wind, PV and storage co-generation panorama monitoring system

reactive power and voltage control, etc. Logical relationship among those applications is shown in Fig. 2.

\section{Key technologies and their application}

\subsection{Day-ahead optimal dispatching}

There are two key requirements of wind, PV and storage co-generation system in the day-ahead optimal dispatching. One is to keep generation curve smooth, which means to smooth out the fluctuations caused by the intermittent energy generation using bidirectional characteristics of storage devices. The other is to increase the integration capacity of intermittent energy. Based on short-term prediction of renewable energy generation, reasonable schedules are drawn up and expected to ensure maximum integration capacity of renewable energy.

\subsubsection{Problem formulation}

Smoothing model could be achieved in two ways: constrained or objective. The latter model is adopted here.

1) Objective function

The objective of co-generation schedule is to maximize the deviation between integration revenue of the co-generation system and penalty cost of power fluctuation: $\max f=\sum_{t=1}^{T}\left[C_{t} P_{t}-\Delta S_{t}\right]$

where $T$ is the interval numbers in a schedule period; $P_{t}$ is the total co-generation schedule over time interval $t$; $C_{t}$ is the generation revenue per unit; $\Delta S_{t}$ is the penalty cost of power fluctuation. The objective is a superposition of generation revenue and penalty cost. Since generation revenue can be used to measure the integration benefits of co-generation directly, the penalty cost has also been given certain economic significance. The penalty cost is the mechanical wear of thermal units, caused by the regulation of power output to meet the requirement of co-generation schedule.

In order to ensure that the generation revenue and penalty cost are in the same dimension, the penalty cost is normalized to the dimension of generation revenue. The formulation is

$\Delta S_{t}=\lambda C_{t} \Delta_{t}$

where $\Delta_{t}$ is the power fluctuation of co-generation schedule over time interval $t$ and obtained by formulating a smoothing model for co-generation schedule. $\lambda \in(0,1)$ is the offset scale factor of generation revenue per unit caused by power fluctuation. Thus, when co-generation schedule fluctuates, the total revenue will be reduced after superimposed on the penalty cost and will in turn suppress the fluctuation of the schedule. 
2) Constraints

The main constraints are listed as follows.

a) System power balance

$\sum_{w=1}^{N_{w}} P_{w, t}+\sum_{v=1}^{N_{v}} P_{v, t}+P_{c, t}+P_{d, t}=P_{t}$

where $N_{W}$ is the number of wind farms; $P_{w, t}$ is the power output of the wind farm $w$ over interval $t$; $N_{V}$ is the number of PV power stations; $P_{v, t}$ is the power output of the PV power station $v$ over interval $t ; P_{c, t}$ is the power of storage plant in charging mode over interval $t$; and $P_{d, t}$ is the power of storage plant in discharging mode over interval $t$.

b) Wind generation power output

$0 \leq P_{w, t} \leq P_{0, w, t}$

where $P_{0, w, t}$ is the forecasting power output of the wind farm $w$ over interval $t$.

c) PV generation power output

$0 \leq P_{v, t} \leq P_{0, v, t}$

where $P_{0, v, t}$ is the forecasting power output of the PV power station $v$ over interval $t$.

d) Inverter power output of storage plant in charging and discharging mode

$-P_{\text {inv }} \leq P_{c, t} \leq 0$

$0 \leq P_{d, t} \leq P_{i n v}$

where $P_{i n v}$ is the allowed inverter power output of storage plant.

e) Capacity constraints of storage plant

Charging energy for each interval:

$E_{c, t}=\alpha P_{c, t} d t$

Discharging energy for each interval:

$E_{d, t}=\beta P_{d, t} d t$

where $\alpha$ is the efficiency coefficient in charging mode; $\beta$ is the efficiency coefficient in discharging mode.

The stored energy of storage plant at the end of each interval is

$E_{t}=E_{t-1}+E_{c, t}-E_{d, t}$

$E_{0}=E_{\text {ini }}$

where $E_{\text {ini }}$ is the initial stored energy of storage plant.

Capacity limits:

$E_{\min } \leq E_{t} \leq E_{\max }$

where $E_{\max }$ and $E_{\min }$ are the upper and lower capacity limit of storage plant respectively.
3) Smooth modeling

For co-generation system, its modeling solution should consider multi-period coupling changes to avoid sharp swings of total power output. A power fluctuation penalty is added into the objective function. There are two methods for modeling of the penalty: three-point coupling smoothing model and two-point coupling smoothing model.

a) Three-point coupling smoothing model

This model considers the changes of the cogeneration power output during three adjacent periods. And the mathematical model is

$\Delta_{t}=\left|\left(P_{t+1}-P_{t}\right)-\left(P_{t}-P_{t-1}\right)\right|$

It's mainly used for reducing the frequency of fluctuations.

b) Two-point coupling smoothing model

This model considers the changes of the cogeneration power output during two adjacent periods. And the mathematical model is

$\Delta_{t}=\left|P_{t}-P_{t-1}\right|$

This model is mainly used for reducing the magnitude of fluctuations.

Linear programming (LP) algorithm has been widely applied in practical systems because of its advantage of fast computational speed and reliable convergence. After linearization of optimization model, this paper solves the optimal problem by adopting a commercial package CPLEX. CPLEX is a sophisticated and computationally efficient solution that can handle thousands of variables.

\subsubsection{Case study}

Based on measured data of the demonstration project, a study case is constructed and a series of numerical analysis is carried out. The case includes two wind farms with installation capacity of $100 \mathrm{MW}$, a PV power station with installation capacity of $40 \mathrm{MW}$, and a storage power plant with capacity of $20 \mathrm{MW}$. The co-generation system is connected to the grid via a $220 \mathrm{kV}$ substation. On the basis of daily forecasting data of wind power and PV power, day-ahead generation scheduling is optimized and drawn up in 96 periods. The time period is $15 \mathrm{~min}$.

Related information of the storage plant is described as follows. Upper and lower capacity limits are $50 \mathrm{MWh}$ and $5 \mathrm{MWh}$ respectively. Initial stored energy is $10 \mathrm{MWh}$. Allowed maximum inverter power output is $50 \mathrm{MW}$. The 
efficiency coefficient in charging mode is 0.8 , while the efficiency coefficient in discharging mode is 1 .

Predictive power outputs of wind farms and PV power station are shown in Fig. 3.

Fig. 4 shows the accumulated forecasting power of wind farms and PV power station. The optimized total power of the co-generation system is drawn as well. The charging and discharging result of the storage plant is shown in Fig. 5. Stored energy of the storage plant is described in Fig. 6.

The above results show that the optimized fluctuation of accumulated power of wind farms and PV power station is

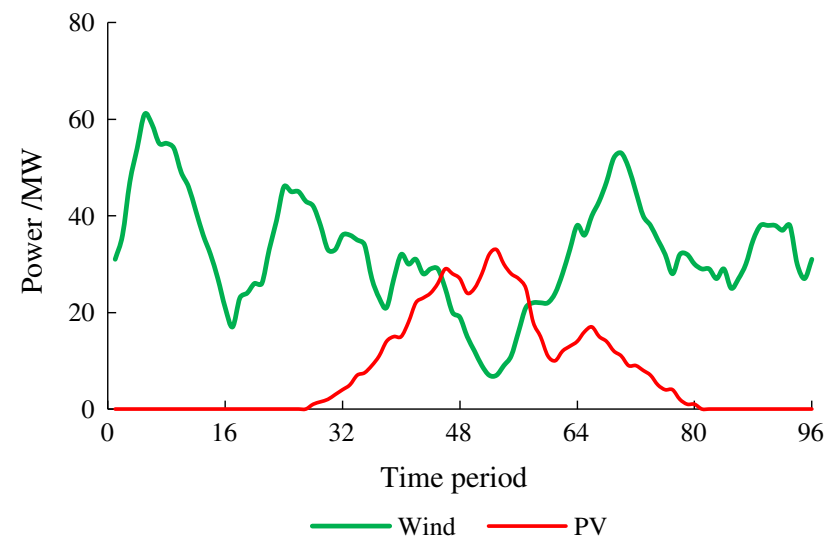

Fig. 3 Forecast of renewable energy generation

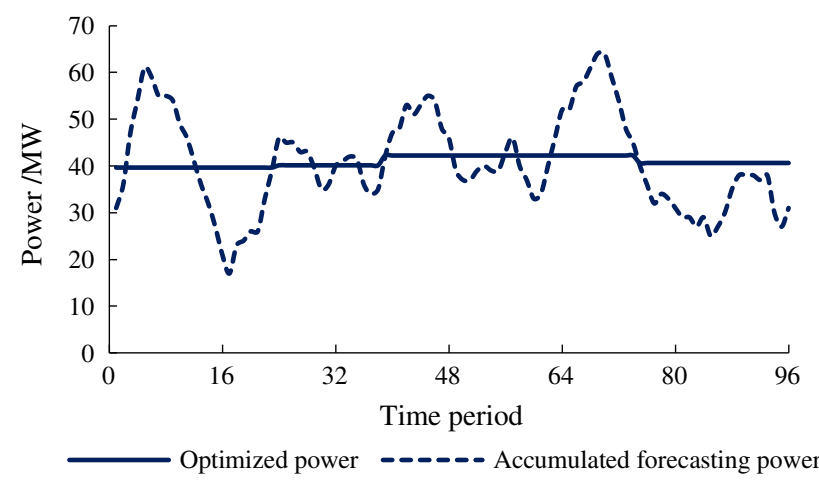

Fig. 4 Optimized results of the co-generation system

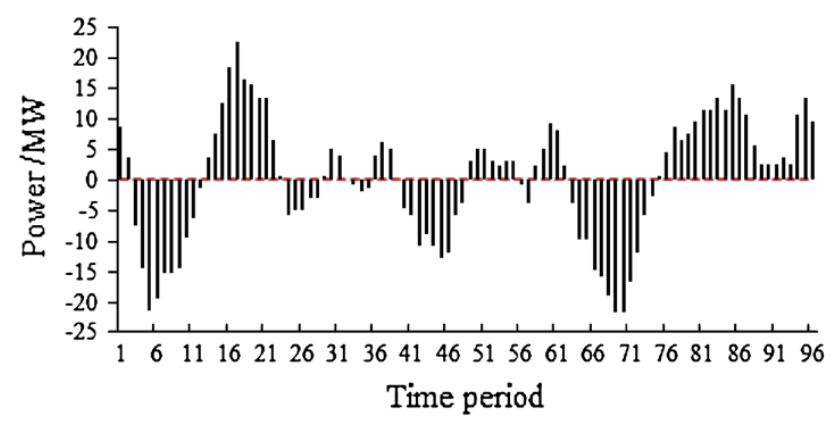

Fig. 5 Optimized charging and discharging result of the storage plant

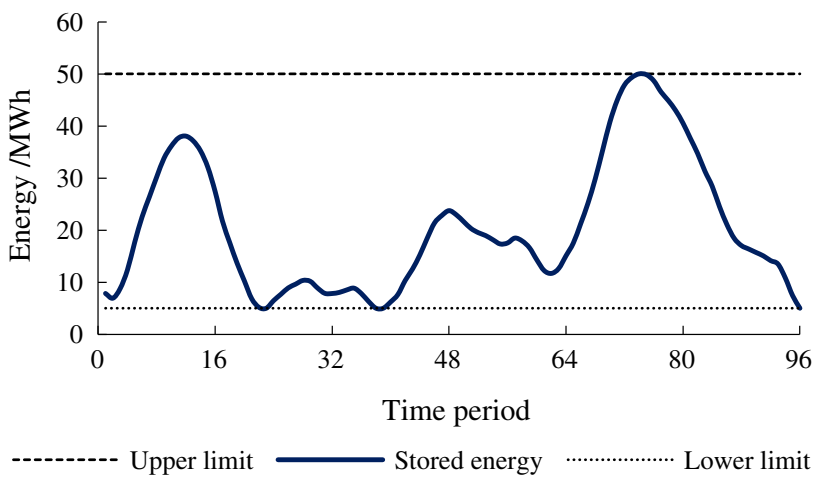

Fig. 6 Stored energy of the storage plant

restrained by the storage plant. The power output of the cogeneration system keeps at a certain constant value. The curve of total power output is comparatively smooth and ideal.

Fig. 6 shows that stored energy of the storage plant reaches its lower limit at period 23 and 39, and it reaches the upper limit at period 74. These limitations lead to the variations of the co-generation system power output.

\subsection{Active power coordinated control}

Active power coordinated control is utilized for further promoting the grid-friendly characteristic of the co-generation system.

\subsubsection{Overall scheme}

Real-time operation of the co-generation system involves various operating configurations. Its control objection may keep changing according to different power regulation demands. They all raise the difficulty of dispatching. As a result, this part presents two fundamental control modes: plant and station control mode, co-generation control mode.

Regarding diverse features and control requirements, control modes for wind farms, PV power station and storage plant are designed to cope with different scenarios. These control modes include output maximization mode, schedule tracking mode, output limit mode, reserve mode and automation mode.

Co-generation control mode is used to describe the global run mode of the co-generation system. In this paper, a kind of co-generation operation with coordinated multiobjective control is realized, the power generation resources are all combined properly. For each operation mode, corresponding control modes are listed in Table 1.

\subsubsection{Control strategy}

The control objects are determined by the operation mode, while the control objectives are decided by the 
Table 1 List of operation and control modes

\begin{tabular}{llll}
\hline Operation modes & Control modes & \\
\hline Wind-PV-ES & Smoothing & $\begin{array}{c}\text { Tracking AGC attaching } \\
\text { superior dispatching centre } \\
\text { Tracking schedule }\end{array}$ & Tracking schedule \\
$\begin{array}{l}\text { WV-ES } \\
\text { Wind-PV }\end{array}$ & Smoothing & Tracking a setting object \\
$\begin{array}{l}\text { Wind alone } \\
\text { PV alone } \\
\text { Storage alone }\end{array}$ & Free power generation & Tracking schedule & Tracking a setting object \\
\hline
\end{tabular}

control mode. In accordance with features among objective functions, control modes can also be distinguished as smoothing control mode and tracking control mode.

1) Smoothing control mode In smoothing control mode, the storage plant is used to smooth the fluctuations of power output. The fluctuation is possibly caused by wind power, PV generation, or wind and PV co-generation. For the storage plant, a state of charge (SOC)-feedback, which is built upon traditional one-order low pass filter to avoid excessive charge-discharge, is added to the control loop. The control block diagram is interpreted in Fig. 7.

where $P_{w p}$ is the power input of wind and PV cogeneration; $P_{w p b}$ is the power output of wind, PV and storage co-generation; $P_{b 0}$ is the charge-discharge power which is obtained by one-order low pass filter; $P_{b}$ is the revised charge-discharge power which is gained by accounting SOC; $T$ is the time constant of one-order low pass filter; $B$ is the compensation coefficient; $K$ is the feedback gain; and $O_{\text {offset }}$ is the offset compensation and used to guarantee the storage devices to be in the optimum area.

2) Tracking control mode

Wind, PV and storage co-generation system can provide steady power output as planned. But the premise is the coordination with the storage plant and real-time bias compensation. This part puts forward a

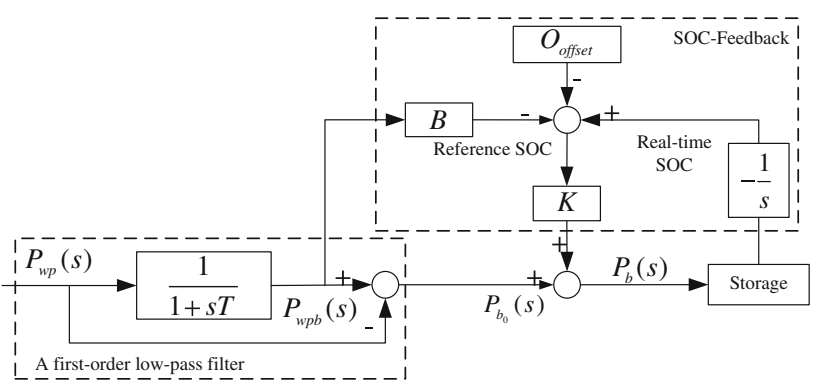

Fig. 7 Block diagram of the SOC-feedback control kind of tracking control strategy. The principle of the strategy is to bundle wind energy generation and PV generation, then decouple the control of storage energy. The intermittent energy generation plants and the storage plant have relatively independent control target.

In order to maximize the utilization of wind and PV resources, wind farm and PV should produce maximum power if the storage plant has sufficient storage space. Thus, for wind and PV co-generation, the objective function can be written as

$P_{w p \_d e s}(t)=P_{r e f}(t)+\Delta P_{b \max }(t)$

where $P_{w p \text { des }}(t)$ is the ideal objective of wind and PV co-generation at period $t ; P_{\text {ref }}(t)$ is the tracked reference objective at period $t$; and $\Delta P_{b \max }(t)$ is the allowed maximal charged power of the storage plant at period $t$.

After decoupling, the real-time output objective of the storage plant is the deviation between real-time cogeneration power and reference objective. The ideal adjustment can be written as

$\Delta P_{b}(t)=P_{r e f}(t)-P_{w p b}(t)$

where $\Delta P_{b}(t)$ is the ideal adjustment of the storage plant at period $t$; and $P_{w p b}(t)$ is the output of wind and $\mathrm{PV}$ co-generation at period $t$.

\subsubsection{Application}

1) The effect of smoothing control mode In Wind-PV-ES operation mode, power output with smoothing control mode (within an hour) is shown in Fig. 8.

The grid-connected technology specification of wind farm and PV power station has clarified the maximum variation of power fluctuations, but the degree of fluctuations is not evaluated. To quantify the smoothing effect of the storage plant, a volatility index $\boldsymbol{\alpha}$ is introduced. 


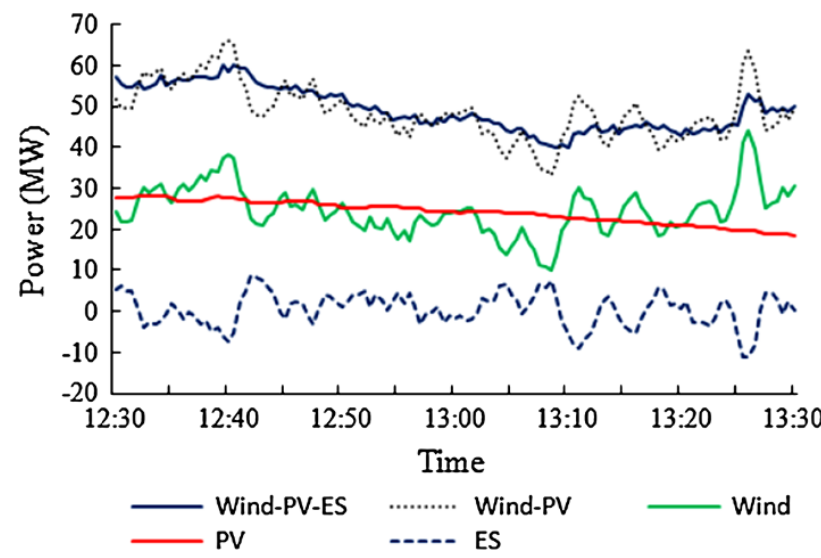

Fig. 8 Power output of Wind-PV-ES co-generation in smoothing mode

$$
\alpha=\frac{P_{\max , 1 \min }-P_{\min , 1 \mathrm{~min}}}{P_{a v g, 1 \mathrm{~min}}} \times 100 \%
$$

where $P_{\max , 1 \mathrm{~min}}$ is the upper limit of power output within $1 \mathrm{~min}$; $P_{\min , 1 \mathrm{~min}}$ is the lower limit of power output within $1 \mathrm{~min} ; P_{a v g, 1 \mathrm{~min}}$ is the average power output within $1 \mathrm{~min}$.

Fig. 9 draws the volatility index $\boldsymbol{\alpha}$ of Wind-PV-ES cogeneration power output before and after smoothing. It can be found that the volatility index of Wind-PV cogeneration power output is generally around $10 \%$. After smoothing, the average volatility index decreases from $7.97 \%$ to $4.39 \%$. It shows that the volatility index is notably improved.

2) The effect of tracking control mode

In Wind-PV-ES operation mode, the effect of tracking control mode (within an hour) is shown in Fig. 10.

In Wind-PV-ES operation mode, control precision within an hour in tracking control mode is listed in Table 2.

As is shown above, in case the regulation reserve of the storage plant is sufficient, control errors within an hour are all below $10 \%$. The proportion of the points with a

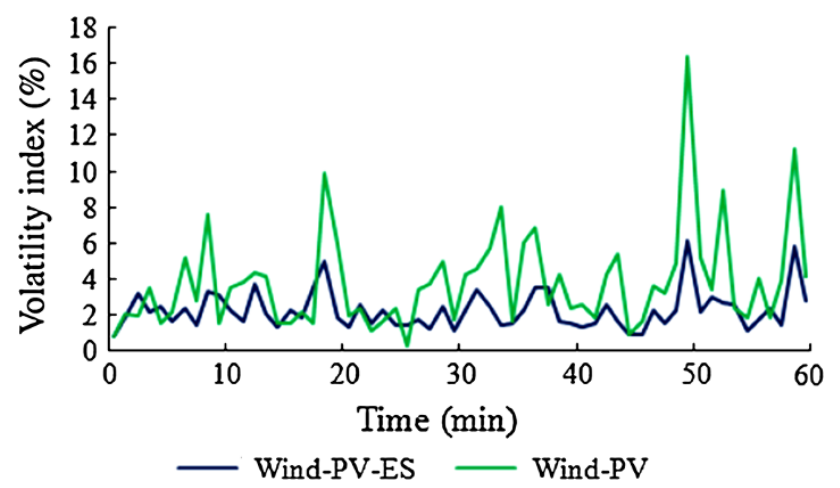

Fig. 9 Comparison of volatility

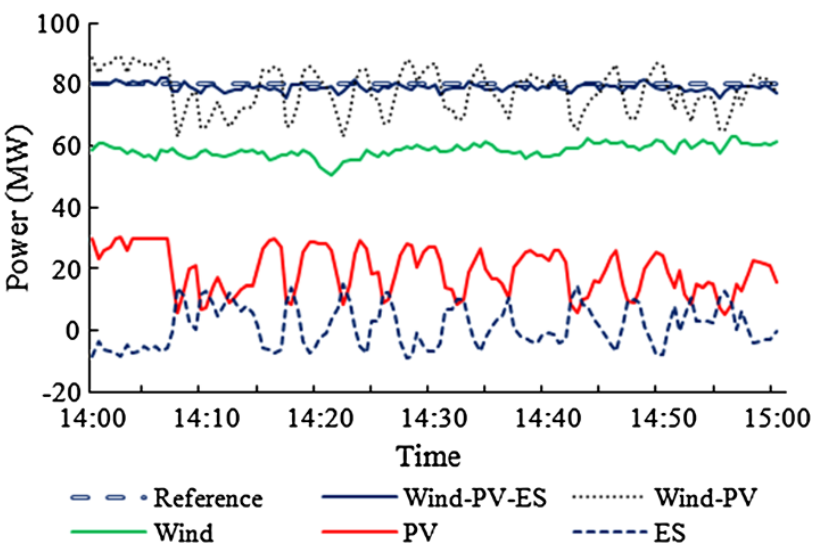

Fig. 10 Power output of Wind-PV-ES co-generation in tracking mode

Table 2 Control precision in tracking mode

\begin{tabular}{|c|c|c|c|}
\hline & \multicolumn{3}{|c|}{ Control error/ $\eta$} \\
\hline & $<10 \%$ & $<5 \%$ & $<3 \%$ \\
\hline Percent & $100 \%$ & $98.35 \%$ & $92.56 \%$ \\
\hline
\end{tabular}

control error percent below $5 \%$ is $98.35 \%$. The proportion comes to $92.56 \%$ with a control error below $3 \%$. This verifies the effectiveness of the control. The power output characteristic of the Wind-PV-ES co-generation system can be similar to that of the conventional power sources.

\subsection{Reactive power and voltage control}

Each reactive power regulating device has its difference in regulating performance in the co-generation system. So a major point of this part is to research the coordinated control among various reactive power sources.

\subsubsection{Overall scheme}

According to the hierarchical voltage regulation principle [16], the structure of reactive power and voltage control can be divided into two levels in this system.

1) Primary control: In this level, SVG attempts to compensate voltage fluctuation caused by rapid variations of renewable energy. It is expected to maintain the constancy of the voltage of $35 \mathrm{kV}$ bus. This cycle will be in milliseconds.

2) Secondary control: The object is to keep the voltage of the injection point at the desired reference values. It is realized through coordinated control among SVGs, wind turbines, inverters and capacitors. The control 
cycle will be set up from $30 \mathrm{~s}$ to $5 \mathrm{~min}$.

SVG is expensive and limited by its installed capacity, which makes it a precious reactive power resource. Thus, the general ideas for coordinated control are as follows. Wind turbines, PV inverters and storage devices are given priority during regulating process. SVG is expected to respond as soon as possible. Capacitor switching acts as a supplementary method. Taking full advantage of reactive power regulation capability of renewable energy generation, we can own maximum dynamic reactive power reserve of SVG and carry out minimum number of capacitors action.

\subsubsection{Control strategy}

Reactive power and voltage control can be divided into two steps: statistical calculation for regulatory demand and assignment among multi-sources as illustrated in Fig. 11.

Assignment strategy among multi-sources is the core link throughout this process. Reactive power demand is distributed among those reactive power sources in reasonable orders. There are two different implementations that include voltage tracking mode and reactive power replacement mode. The latter one is expected to keep maximum dynamic reactive power capability of SVG and provide constant total reactive power.

Based on calculation results, adjustment target for each feeder will be determined according to equal power factor principle.

\subsubsection{Application}

1) The effect of voltage tracking mode

Fig. 12 shows the effect of voltage tracking control. Take the following case as an example. The reference voltage was changed from $230 \mathrm{kV}$ to $225 \mathrm{kV}$ at 14:31:10 on December 23, 2011. The dead zone of command was set at $1 \mathrm{kV}$. At this point, real-time voltage was $230.5 \mathrm{kV}$, with a $5.5 \mathrm{kV}$ deviation from reference voltage, which obviously exceeded the dead zone. Hence the co-generation monitoring system

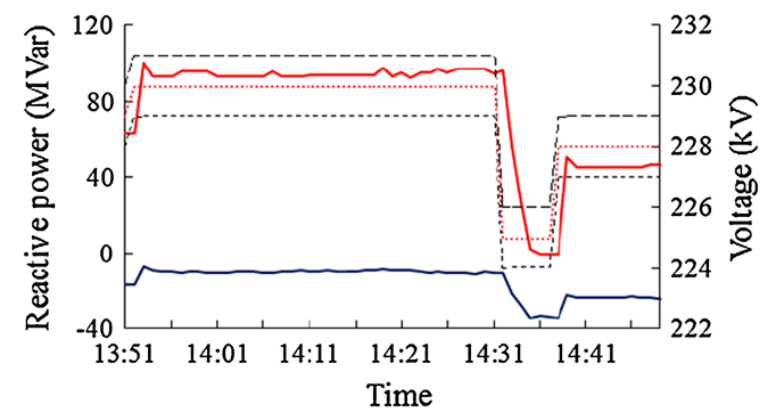

$\begin{array}{ll}\text { - Reactive power injection }- \text { Real-time voltage } & \cdots \cdots \cdot \cdots \cdot \text { Reference voltage } \\ --- \text { Upper limit of voltage } \quad \cdots . . & \text { Lower limit of voltage }\end{array}$

Fig. 12 Effect of voltage tracking mode

started to control immediately. At 14:34:10, real-time voltage was adjusted to $230.5 \mathrm{kV}$, with a $0.5 \mathrm{kV}$ deviation from reference voltage which met the control requirements. Meanwhile, reactive power of the injection point was varied from -18 MVar to -30 MVar.

Fig. 13 shows the control sequence of all devices in the same section. Voltage of the $35 \mathrm{kV}$ bus, which connects with SVG, dropped gradually from $37.2 \mathrm{kV}$ to $35.7 \mathrm{kV}$. Reactive power of Xiaodongliang wind farm varied from 3.8 MVar to -3 MVar. And the voltage of PV power station decreased from $5 \mathrm{MV}$ ar to $0 \mathrm{MVar}$.

It can be concluded that the above-mentioned regulating process can rapidly track the voltage of the injection point at $220 \mathrm{kV}$ bus. And the control effect is satisfying. The rate of regulation is greater than $1 \mathrm{kV} / \mathrm{min}$.

2) The effect of reactive power replacement mode While active power is stable, co-generation monitoring system will start to adjust low-speed reactive power resources to substitute for capacity of SVG, thus it increases the dynamic reactive power reserves. The capability to smooth the rapid voltage fluctuations will be reserved consequently. Fig. 14 shows the control sequence of all devices on Dec.19, 2011.

During that period, active power of the co-generation system was relatively steady. The voltage of the $35 \mathrm{kV}$ bus remained around $37 \mathrm{kV}$. Reactive power of the $\mathrm{SVG}$

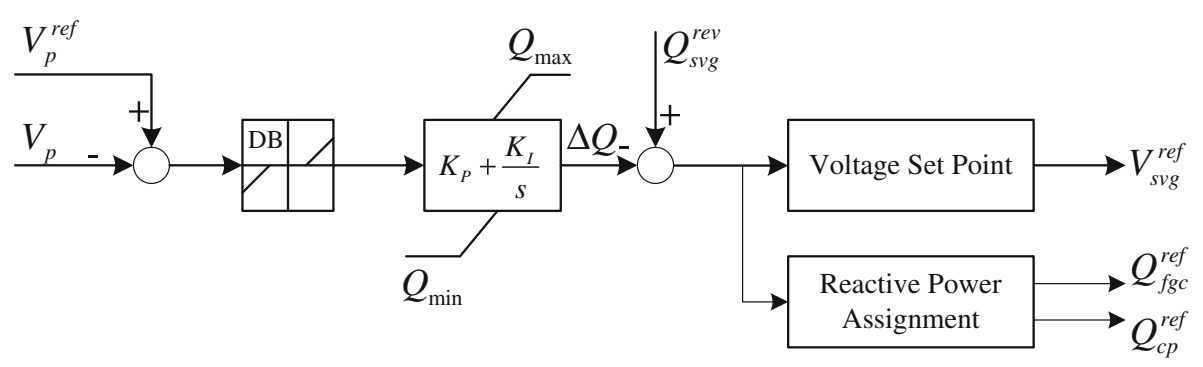

Fig. 11 Schematic diagram of reactive power and voltage control 


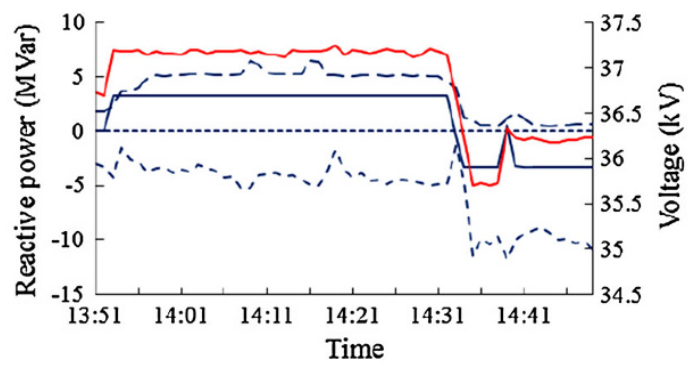

- Reactive power of Xiaodongliang wind farm - - Reactive power of PV power station - - -Reactive power of the SVG

----Reactive power of capacitors

- Voltage of the $35 \mathrm{kV}$ bus

Fig. 13 Control sequence of reactive power sources for voltage control

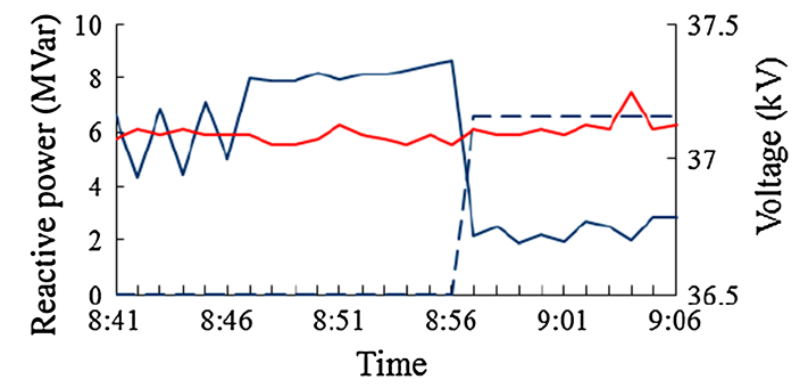

- Reactive power of the SVG $\quad--$ Reactive power of capacitors

- Voltage of the $35 \mathrm{kV}$ bus

Fig. 14 Control sequence of reactive power sources under reactive power replacement mode

kept around 8 MVar before 8:56. At 8:56, capacitors were ordered to put into regulation, reactive power of the SVG started to adjust and gradually dropped to 2 MVar. In other words, dynamic reactive power capability of SVG was improved.

\section{Conclusions}

Wind, PV and storage co-generation monitoring system has been implemented in the demonstration project. With several months of trial operation, the project is stable and reliable. Complementary advantages of each participant are made to the most. Power output of the co-generation system is grid-friendly and is similar to conventional power sources. Regulation characteristic of grid-connected voltage is improved. Grid capability to accept renewable energy is effectively improved.

Both theory and practice prove that it is feasible to make use of renewable energy resources through wind, PV and storage co-generation mode. This will be one of the developing directions for utilization of renewable energy resources and a demonstrative case for large-scale renewable energy power integration.

Open Access This article is distributed under the terms of the Creative Commons Attribution License which permits any use, distribution, and reproduction in any medium, provided the original author(s) and the source are credited.

\section{References}

[1] Wang CS, Wang SX (2008) Study on some key problems related to distributed generation systems. Automat Electr Power Syst 32(20):1-4 (in Chinese)

[2] Sun YZ, Wu J, Li GJ (2007) Influence research of wind power generation on power systems. Power Syst Technol 31(20):55-62

[3] Zhao ZM, Lei Y, He FB et al (2011) Overview of large-scale grid-connected photovoltaic power plants. Automat Electr Power Syst 35(12):101-107 (in Chinese)

[4] Barton JP, Infield DG (2004) Energy storage and its use with intermittent renewable energy. IEEE Trans Energy Convers 19(2):441-448

[5] Tan CW, Green TC, Hernandez-Aramburo CA(2007) A stochastic simulation of battery sizing for demand shifting and uninterruptible power supply facility. In:Proceedings of the IEEE Power Electronics Specialists Conference(PESC'07), Orlando, FL, USA, 17-21 June 2007, pp 2607-2613

[6] Bhargava B, Dishaw G (1998) Application of an energy source power system stabilizer on the $10 \mathrm{MW}$ battery energy storage system at Chino substation. IEEE Trans Power Syst 13(1):145-151

[7] Billinton RB (2006) Reliability considerations in the utilization of wind energy, solar energy and energy storage in electric power systems. In: Proceedings of the International Conference on Probabilistic Methods Applied to Power Systems (PMAPS'06), Stockholm, Sweden, 11-15 June 2006, 6 pp

[8] Huang SZ, Dai ZQ, Ma XP (2010) Design and realization of computer integrated monitoring system of wind farm. Jiangsu Electr Eng 29(1):38-40 (in Chinese)

[9] Qiao Y, Lu ZX, Xu F et al (2011) Study on the integrated monitoring \& control platform of wind farms. Power Syst Protect Contr 39(6):117-123 (in Chinese)

[10] Wang CF, Li R, Liu HR et al (2011) The design and implementation of photovoltaic power generation monitor control system. Telecommun Electr Power Syst 32(6):53-57 (in Chinese)

[11] Zhao M, Lu JZ, Zhou RJ et al (2011) The small-scale wind-solar hybrid grid-connected generation system. Hunan Electr Power 31(1):10-13 (in Chinese)

[12] Yu P, Zhou W, Sun H et al (2011) Hybrid energy storage system and control system design for wind power balancing. Proc CSEE 31(17):127-133 (in Chinese)

[13] Li JX, Zhang JC, Zhou Y (2011) Energy management strategy of wind-PV-ES hybrid power system. East China Electr Power 39(12):2026-2028 (in Chinese)

[14] Feng LM, Fan GY, Zheng TY et al (2011) Design of wind power dispatch automation system in Jilin power grid. Automat Electr Power Syst 35(11):39-43 (in Chinese)

[15] Bai YX, Fang DZ, Zhu CS (2011) Design and application of wind farms dispatching and management technical support system in Inner Mongolia power grid. Automat Electr Power Syst 35(7):86-90 (in Chinese) 
[16] Vu H, Pruvot P, Launay C et al (1996) An improved voltage control on large-scale power system. IEEE Trans Power Syst 11(3):1295-1303

Xianliang TENG received the B.E. degree in 2000 from Zhengzhou University of Technology and M.E. degree in 2011 from Southeast University. Currently, he is working at NARI Group Corporation, China. His work has been in power system dispatch and control, renewable energy generation and its integration.

Zonghe GAO received the M.E. degree in 1989 from State Grid Electric Power Research Institute (SGEPRI), Nanjing, China. Currently, he is the Managing Director of Nanjing Power Grid Dispatching \& Control Technology Branch Company, NARI Group Corporation. His work has been in the power system dispatch and control.

Yingyuan ZHANG received the Ph.D degree in 2011 from Hefei University of Technology, Anhui, China. Currently, she is working at
NARI Group Corporation, China. Her work has been in the power system dispatch and control.

Hua HUANG received the M.E. degree in 2001 from Huazhong University of Science and Technology, Wuhan, China. Currently, he is working at NARI Group Corporation, China. His work has been in the power system dispatch and control, especially voltage control and reactive power optimization.

Lili LI received the M.E. degree in 2011 from State Grid Electric Power Research Institute (SGEPRI), Nanjing, China. Currently, he is working at NARI Group Corporation. His work has been in the power system operation and optimization.

Tingting LIANG received the B.E. degree in 2004 from Northeast electric power University, Jilin, China. Currently, she is working at Zhangjiakou Wind and Solar Power Energy Demonstration Station Co. Ltd. Her work has been in the renewable energy generation and its integration. 